\title{
Study on a Heritage Town in the Northern Badia of Jordan-Al Aqeb
}

\author{
Mohannad Tarrad \\ Department of Architecture Engineering, Faculty of Engineering, Al-Bayt University, Mafraq 25187, Jordan
}

\begin{abstract}
This field study in $\mathrm{Al}$ aqeb town and its surroundings is a result of joint research between two scientific fields: anthropology and architecture, where the researchers interested in the local community in terms of social, stability method, patterns of production and its transformations, as well as in physical culture for population in traditional, heritage and modern housing, and the reason to choose $\mathrm{Al}$ aqeb is to test the stability of the nature of pastoral groups in $\mathrm{Al}$ aqeb basin and valley which are available on pastures and water sources and the remains of ancient centers of human settlement which provides building materials to create traditional dwellings made up of basalt stones and mud where the researcher use the field surveys methodology in the target area through field trips and description of heritage sites and architectural field studies methodology in terms of description, analysis and measuring and drawing. And study populations and pastoral aspects, features of the surface and material evidence. The Bedouin human interacts with its environment depending on its own style in simple techniques to meet his basic needs of physical, cultural and the need for shelter and housing.
\end{abstract}

Key words: Housing pastoral, Badia of Jordan, local Jordanian, community racialist history.

\section{Introduction}

$\mathrm{Al}$ aqeb is a pastoral farming town, located on the eastern end of the $\mathrm{Al}$ aqeb valley, $25 \mathrm{~km}$ east of Mafraq city, specifically the town located on the southern edge of the desert through Mafraq-Baghdad. It was founded as a village in 1935 on the impact of the stability group of the family of Al_guenis $\mathrm{Al}_{\text {_msaeed }}{ }^{1}$ of $\mathrm{Al}$ _msaeed clans from the mountain Bedouin $^{2}$, with a population according to statistics of 2010: 4,500 people in about 650 dwellings, where they were traveling before the stability in the pastures of the surrounding villages of Bosra, Hauran, Asamakiet, Mrabh, Nemrah and Algaria as you can

\footnotetext{
Corresopnding author: Mohannad Tarrad, Dr., research fields: architectural and heritage. E-mail: mc_tarrad@yahoo.com.

${ }^{1}$ Masaeed: Bedouin tribe originally from the Hejaz, deployed in the country Najd, Iraq and Egyptian Diyar and in areas of southern Syria and northern Jordan, known as the people of the mountain relative to the al-Arab mountain in the Hauran, live in the northern Badia of Jordan.

${ }^{2}$ The people of the mountain: the settled groups in the mountain and plains of southern Hauran (southern Syria) and Jordanian northern desert and their families: Zubaid, Alshorofat, Alazamat, Masaeed and Alghyatht.
}

see in Fig. 1.

It is called $\mathrm{Al}$ aqeb, relative to the valley because its water keeps track of water flow of most Badia valleys, and most of its tributaries coming from Jebel Hauran south of Syria. Northern and western Badia areas in the basin of $\mathrm{Al}$ aqeb valley were undergone for early archaeological studies including:

- Butler, H.C. Publications of the Princeto university Archaeological Expedition to Syrian;

- Betts, Alison, Black desert survey, Jordan third preliminary Reporting.

\section{Study Objectives}

The study aims to document the experience of Bedouin stability during the historical successive periods on site, and find out ways and means of livelihood and cultural achievements, means of exploitation of the elements of environmental benefit of the vital area in the basin of the valley of $\mathrm{Al}$ aqeb which rich in archaeological and heritage elements, through field studies, anthropological and architectural, can be found at urban and social history 


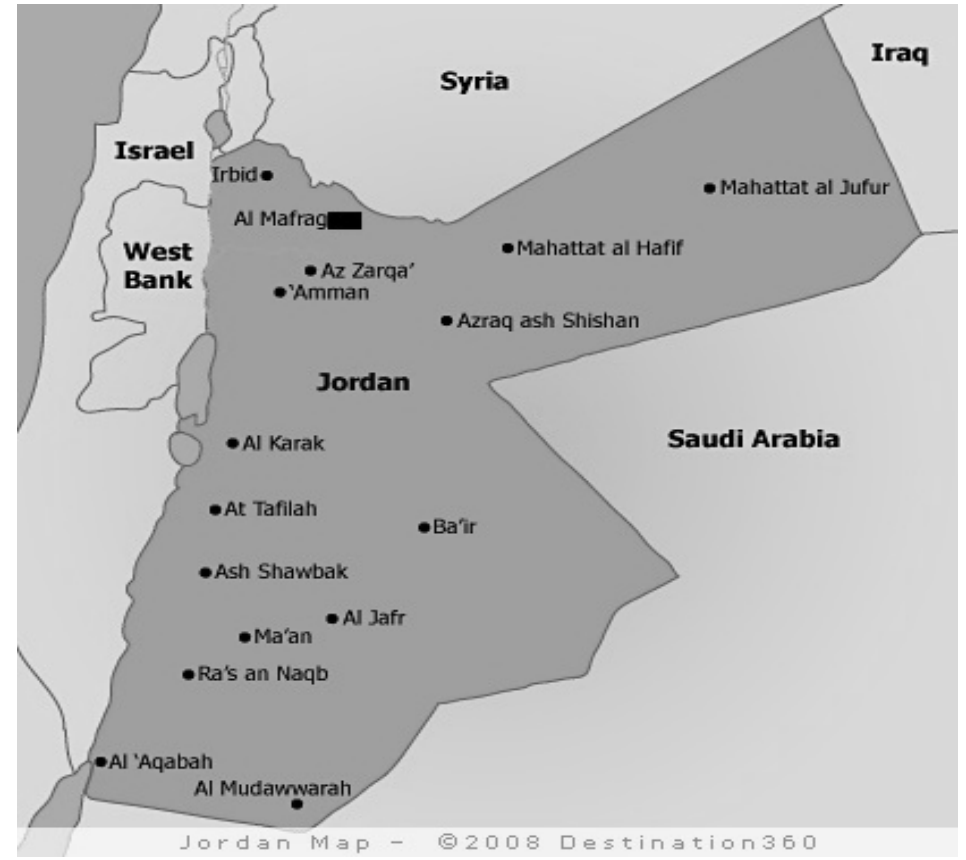

(a)

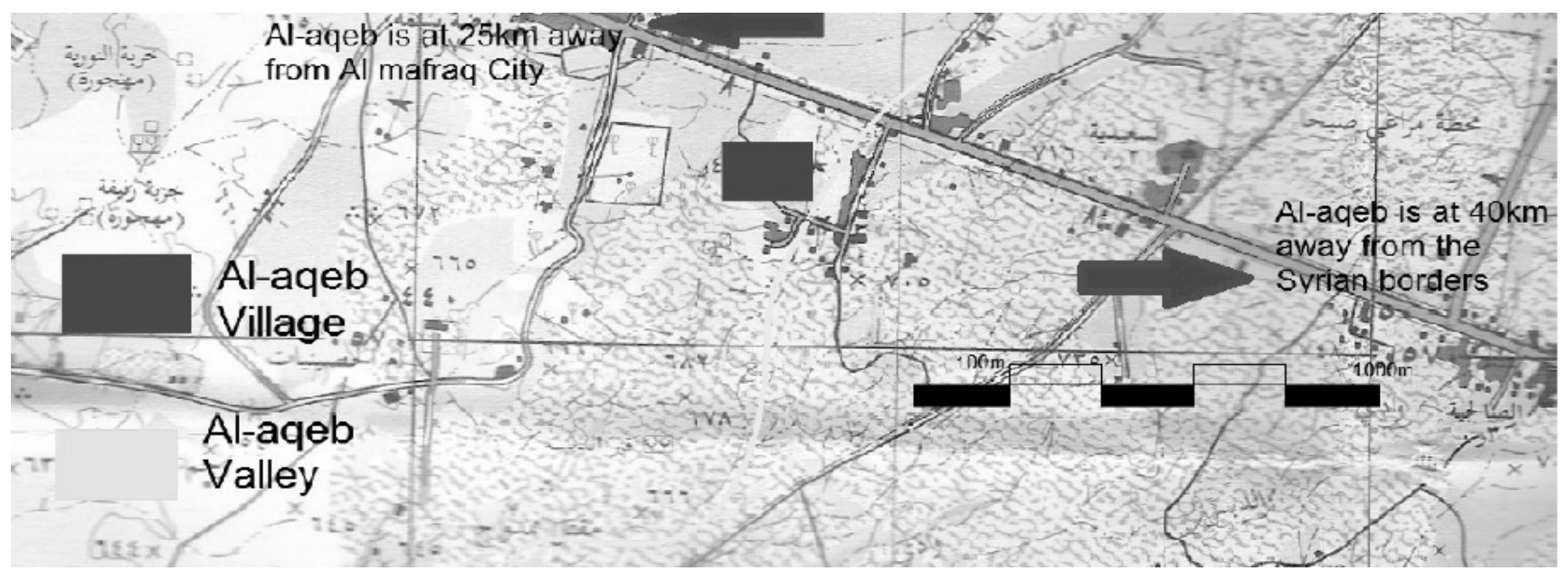

(b)

Fig. 1 (a) The map of study site; (b) the course of the valley of Al aqeb which passes in the town (the study site).

and preserve the memory of the place especially since the Badia region exposed to rapid radical changes as a result of several natural and human factors.

The study introduce a hypothesis that are Al aqeb depend on its self components, and are early dwell try to benefit from the vital area of the site and engage in the processes of development, which reflected on the transformation of town's growth from traditional aspects to modernity that prevailed in the villages, towns, countryside and the Badia.

\section{Methodology}

Surveys and studies socio-anthropological field were used in the target area through field trips and description the heritage sites and through architectural field studies in terms of description, analysis, measurement and drawing. And through the study of population and pastoral aspects and features of the surface and physical evidences, use the observation tools and field surveys in the region especially in sites 
that contain natural phenomena and physical evidences of early stability patterns and modern and centers of fishermen, ranchers and temporary and permanent herders and patterns of housing and development.

All observations recorded in the daily field surveys and implementation the initial illustrations and photographs.

\subsection{Interviews}

The interviews adopted in the field surveys as a major source of gathering of information field, and use of the opened interviews, and collect information about how the existence of $\mathrm{Al}$ aqeb, and information about social and architectural history in villages that scattered in study area.

\subsection{Office Work}

Collection the information and various data in the anthropological traditional architectural surveys records, and then write it down to unloaded and sorted according to topics surveys, has been back to written published sources for the region, and the use of descriptive method and geographical-historical method in display article and the data field and view the topics that relate to the natural environment and its distributed according to geographical location of the study area.

\section{The Natural Environment (Environmental Climatic Characteristics)}

\subsection{Geologic Formation}

Geological structure of the region formed from sediments of air and water and from soil transfer that formed in the modern Quaternary age. These sediments spread in most surveys, and shows its high sensitivity of geomorphologic process specially the operations of water erosion, which has had a large role in the formation of valleys and streams. The bazalt rock deployed in the region of medium particles region, which was formed in the Newgens era of
Quaternary time that seen of active weathering and erosion processes led to soil basalt formation, which spread in $\mathrm{Al}$ aqeb valley, this water erosion appeared in the valleys and this processes of erosion vertical reveal the basic rock of valleys where runoff in rainy seasons [1].

\subsection{Morphological Characteristics in Al Aqeb Valley Basin}

The average decline between 3-9 degrees, this has been affected by erosion processes diffusion, past and present as a result of agricultural activities dry and irrigated., residents of the area practice reclaiming and processing the agricultural land that require cleaning the land of basalt stones from the earth's surface which contributed to increase the morphological activity [2].

\subsection{Soil}

A top layer or surface of the fragmented rocks that cover the surface, the soil characteristics contribute in determining the pattern of land use and the type and density of vegetation cover, which fits to the climate of the region, yellow Mediterranean soil and basalt spread in Al aqeb valley basin, characterized by soft and loose particles, especially in the upper level of the surface which increases the thickness of the sediment surface in the valley stream and content of calcium carbonate-which loosely coupled wild herbs infested in and used in rain fed grains agriculture (wheat and barley), the region is witnessing an expansion in tree dense irrigated agriculture on artesian wells. One of the problems encountered in the soil is stones cleaning processes, which making it vulnerable to erosion and intensive exploitation in agriculture, evidenced by the spread of ancient and modern dams, in valley stream, and the effects of stone channels, which had been across the water for long distances for use in irrigated agriculture (citation from page 19 in Ref. [1]).

\subsection{Vegetation}

A vegetation that grows naturally without human 
intervention in its Germination and origination. Natural plant reflects the environmental climate system and human activity, the wild plants spread in the region and in valley stream from type into four types, such as Tarfat AL-Akam (Tamarix Jordanis) which abound in the valleys, Qaysom Achilleasantolina, and Al-Al Sheh (Artemisiaherba-alba), and Al-Esbaeh Al Motajmeah (Dactyisglomcrata) the plant palatable to grazing and other such as Al-Atheal (Tamarixaphylla), and Agrm (Anabasisarticuiata) and wild zaatar (Hajorana Syriaca), and Al-ghar (Laurusnobilis) [3]. The residents mentioned information about Perennial trees that spread in the region in the past, and stated that Butm trees (juniperus) spread in the basin of the valley, bushes was spreading on the edge of the valley became extinct because of the drought, grazing and logging, from this bushes $\mathrm{Al}$ Ghaar (the laurel) where you see its roots on the outskirts of the valley (citation from page 14 in Ref. [2]).

\subsection{Climate}

The region belongs to the eastern Mediterranean climate which makes it exposed to winter air depressions where the climate of the region is characterized by cold rainy winters and relatively short, while the summer is long, hot and dry, the region exposed to the south easterly winds are warm to raise the temperature and active dust storms, and also are working on dismantling the soil and distribute it in the air, especially in flat areas and isolated of stones (citation from page 107 in Ref. [1]).

The temperature is different in daily, monthly and yearly rates, has a rate of 18 Celsius and increases towards south-east, the daily average in January up to 12 Celsius in eastern parts, and the daily yearly average varies to 15 degrees Celsius [4].

\subsection{Water Sources and Irrigation Systems}

$\mathrm{Al}$ aqeb Valley is called $\mathrm{Al}$ aqeb, relative to the Valley because its water keep track of water flow of most Badia valleys, and most of its tributaries coming from Jebel Hauran south of Syria, where the snow gathered on the highlands and then melt on the end of spring where it supplies the valley with water in the period of low level of water of other valleys. Al aqeb Valley is the second largest valley in the free zone in the Badia after Al-Rajel Valley, it is considered a fertilized basin, alluvial red soil of the basalt origin. Valley stream is characterized in the establishment of pastoral and agricultural villages along the valley stream and the expansion of ancient and modern architectural systems and agricultural [5].

\section{The Historic and Social Environment (Archaeological and Heritage Landmarks in Al Aqeb)}

The basins and valleys are a favorable environment for the emergence of human stability where the heritage and cultural landmarks [6], as a result of the pastoral communities stability in $\mathrm{Al}$ aqeb valley basin, a relationship between man as a social being, and the place as a environmental system was established and as a result of that relations the heritage villages was established and these villages where surrounded by pastures, water resources, circular architectural configurations, livestock barns and cemeteries.

\subsection{Old Settlement Manifestations}

It is expressed by the stone architectural circular shape systems, which is located directly adjacent to the valley, where the rocks consist of medium-sized building blocks, punctuated by the entrance is surrounded by a large vertical stone blocks.

\subsection{Cumulus Cemetery}

It is one of the heritage features in $\mathrm{Al}$ aqeb town, which include the remains of ancestors of the founding of the town and includes tombs that are built of natural basalt of stones.

The cemetery is located on the edge of the valley near the water sources, and one of these cemeteries is 
the cemetery of grandma Thabiah Ursaan and the of Zayed Ayaz Alguenis. These tombs are still appreciated and revered by the people of that town.

Burial Hesn is located in the pasture, which lies in the north of $\mathrm{Al}$ aqeb on the eastern edge of the valley where the burial of the cumulus cemetery is, and is deemed to be the Covenant cemetery to one of the pastoralist grandmother groups that had lived on a site called (Hesn) as you can see in Fig. 2.

\subsection{Stability and Composition of Racialist}

In the early thirties of the last century, a group of a family called (Alguenis Almsaid) had settled in the region, to whom they used to visit that place constantly in order to transhumance their cattle. Moreover, people of that site used to move around in the pastures of al (Hauran) before their settling.

Reports showed that the founder of the local village Alaqeb is (Cayenne Alguenis) ${ }^{3}$ where the stability of the site has been firmly established after building fixed houses that are made of basalt stones and mud in the site near to the eastern edge of $\mathrm{Al}$ aqeb valley. In other words, early sedentary people are known to be living in scattered tents at first on the both sides of the valley, and then they rolled after the construction of buildings according to the traditional housing system in the status of the founding families of $\mathrm{Al}$ aqeb town.

\section{Patterns of Production and Income Sources}

The circumstances and environmental conditions have played a key role in achieving and forming the production pattern and for the rest of the economic activities that took place through tracking the social and historical production in the region of $\mathrm{Al}$ aqeb. Field of studies was conducted to assign two stages of production patterns and sources of income and they are:

(1) Phase 1

Known as a traditional pastorl productive which depend on grazing in the pastures in $\mathrm{Al}$ aqeb valley, as

\footnotetext{
${ }^{3}$ Surveys and field studies, Al aqeb, December-January 2012.
}

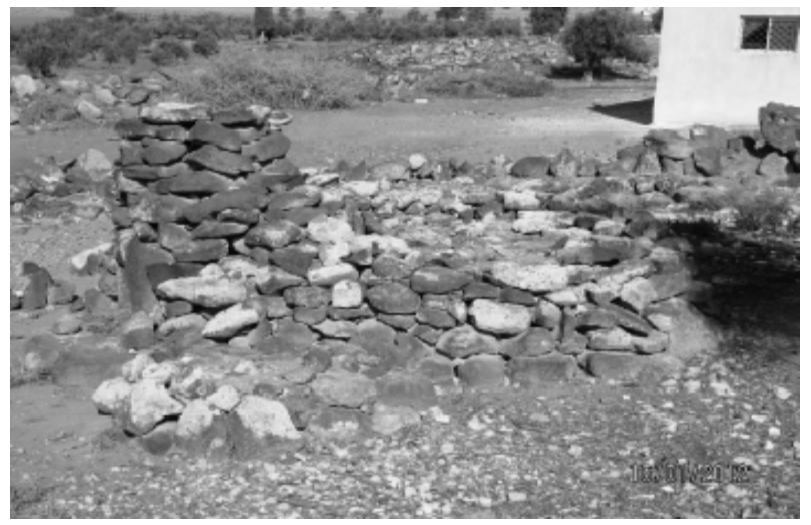

Fig. 2 Graves.

it was practiced by the early sedentary people and by the founders of the town.

In addition to the cultivation of rain grain from $\mathrm{Al}$ aqeb water valley, especially on the agricultural pieces that occurs on the edges, and not to mention, that were carried by water channels through old dam stone which has impeded the valley course;

(2) Phase 2

The second phase was characterized by the new emergence of production forms for modern economic activities which started to appear in the beginning of the last century as a result of the evolution of urbanization and rural transportation, communication and the occurrence of $\mathrm{Al}$ aqeb directly on the desert road (Almafraq-Baghdad), and the spread of official service institutions and their access to the populated developing area and enjoying the services of education, health, electricity and water, where that helped to the emergence of work patterns and new careers in government jobs, trade and military service, work in the service sector of transport and construction, to rely on a fixed income and monthly salary.

\section{Architectural and Urban Composition}

\subsection{Function}

The primary functions: Harboring the family, is a biological needs mainly aim to preserve the preserve of life, and even if that contact with psychological-social requirements. As well as, it 
includes ways of preparing food in the house and other housework form like sleeping, resting, recreation and even harboring livestock.

The elementary functions: It is the socio-cultural needs that include a various types of facilities and necessary services to reach long lasting satisfaction including the privacy of social contacts, resting areas in the reception rooms and including relationships in the tents and housing.

In general, the relationship between the Bedouin man and housing, in other words, between the family and the shelter is a controversial relationship focused upon stability operations and commuting, so the family is a group of private internal organization, and it is a unit of general tribal organization that has various functions (such as securing the continuation of gender, reproduction, upbringing, role and status, and the protection of the tribal livestock), the family cannot make all of these hob without housing.

\subsection{Traditional Patterns of Housing}

\subsubsection{Tents}

Until recently, the population of Badia have lived in a simple tents not only because it is environmentally comfortable but also it is suitable to the nature of their lives in which it depends on the constant moving and traveling behind the water and roaming in Badia pastures.

Houses and equipments are known to be carried on the backs of camels, for many reasons because it can be easily put out and easily taken away, moreover, they are manually manufactured and woven by the Bedouin family women. In addition to that, the materials are taken from the goat hair and the wool of sheep and camel, and that's why is called Beit alshaer.

\subsubsection{Traditional Pastoral House}

(Cayenne Urssan Alguenis Almsaid) Dwelling: These types of houses had appeared in $\mathrm{Al}$ aqeb town in the early fifties of the last century. This house was built in 1953, where a fixed house was built from stone and mud at the edge of the $\mathrm{Al}$ aqeb valley near to the water sources and agricultural terraces. After that, operations of building and construction started soon by architects who came from the south of the Hauran located to the west of the town and specifically according to the following coordinates: " $\mathrm{E}$ = 0396, 41040", “LEVEL = 702”, “N = 32.27789”. The construction of housing composed of architectural rectangular shape stone in which designed as a special resident for the family. Moreover, the dwelling consists of a spacious rectangular room opening to the outer space by a single door opening to the north and that preceded by an opened courtyard as you can see in Fig. 3.

\subsection{Construction Method}

The dwelling consists of one-room about $\left(7 \times 8 \mathrm{~m}^{2}\right.$ and of a height about $(5 \mathrm{~m}$ ) heading towards the main entrance to the north. The method adopted in building houses depend greatly on the basalt stone where stones of basalt are in large quantities in some villages in the northern Badia of Jordan since early ages plus is considered to be the major structural material for

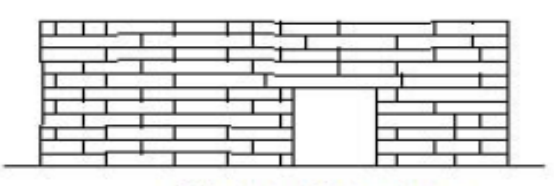

North - Elevation

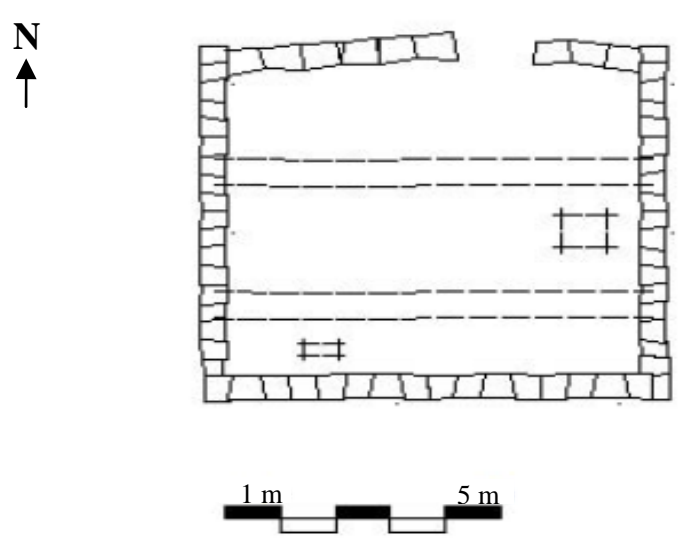

Fig. 3 Traditional pastoral housing in the town of Al aqeb specifically dwelling (Cayenne Ersan Guenis Masaeed). 
building in that region.

The walls of this house were built from a row of irregular basalt stone of thickness about 60 and up to $70 \mathrm{~cm}$ and was roofed according to the corbelling method, which is a prominent part of the wall where the ceiling is built from a basalt stone in the form of overlapped building blocks with the walls. So the outer surface located at the level of the wall surface, the blocks are built over it to make it steady and able to bear the slices that forms the roof, and for the purpose of increasing the breadth span between the walls, another row of corbelling blocks is being used and that extend along the wall.

All of these corbellings were made from slices of basalt stones that have soft and trimmed aspects on the sides, but are crude (Gshema) on the surfaces [7]. Not to mention that this ceiling is based on the internal arch for the buildings that has wide spans. Moreover, it used a semi-circular stone as a structural supportive of the ceilings. These rocky arches are built in the center of the space in which wanted to be roofed based on the walls and a square or cylindrical shape base that are trimmed in a high-tech way, so the slices of stones come and rely on the highest arch of a long trimmed basalt stone variably in which these slices extended to rely on the Arch and so that could rely from the other side on the observed corbellings of the walls. On the other hand, it has been observed that these slices are also trimmed in varying degrees so that these straight edges could overlap next to each other tightly, which increases the degree of cohesion to support the loads and which are distributed on top of the arch stone [8].

This system was used in several buildings in the northern of al Badia, hence it is called the house of (Al Hourani), in other words, this system was used and attributed to the area of (Al Horan), which lies south Syria and north-east of Jordan, but for the holes, it has been observed the absence of holes in blocks except for the door opening, as for ventilation there are two small slots found in ceiling.

\subsection{Primitive Pastoral Housing}

These types of traditional houses had appeared towards the end of fifties of the last century, in addition, researchers have studied two patterns of these houses, and they have found that the construction method differ in loading ceilings, so that it is easier way than the previous one, in which the ceiling can be held on the constructed walls from a basalt stone with a thickness of $30 \mathrm{~cm}$ up to $40 \mathrm{~cm}$ while the slides of stones have been replaced with an iron bridge that goes along length of the house. Moreover, it is followed by row of arrayed iron that has at the top a layer of mud mixed with straw of a thickness not less than $25 \mathrm{~cm}$ which makes the thickness of ceiling and work simple for the drainage of water rain. Furthermore, it can be observed that the interior arches are replaced by interior stone partitions in the same thickness of the outer walls, as for the holes they were all represented in the main hole of the entrance and in some small aperture in the facades, as well as, all of these holes had ran out of basalt stones in a very constructional and architectural way, and all of these apertures topped by a swaddle of a rectangular stone or with a swaddle of arrayed stone at the both sides of aperture.

\subsection{The Dwelling of Raffa Salama Farraj Masaeed}

The house is located on the north side of the town according to the following coordinates, “ $\mathrm{N}$ : 32.269”, “E: 036.40564” “Level: $710 \mathrm{~m}$ ”. The house consists of a mass of architectural rectangular shape built of stones of natural crude basalt. The space of the house reach a $\left(5 \times 12 \mathrm{~m}^{2}\right)$ with a height of $4 \mathrm{~m}$, the dwelling contains two rooms each room opens a door to the east on an open patio surrounded by a series of stones built of a row natural basalt stones as you can see in Fig. 4.

\section{Architectural Description of the Pastoral Assembly}

This pastoral assembly consists of several architectural patterns that are built of different materials 


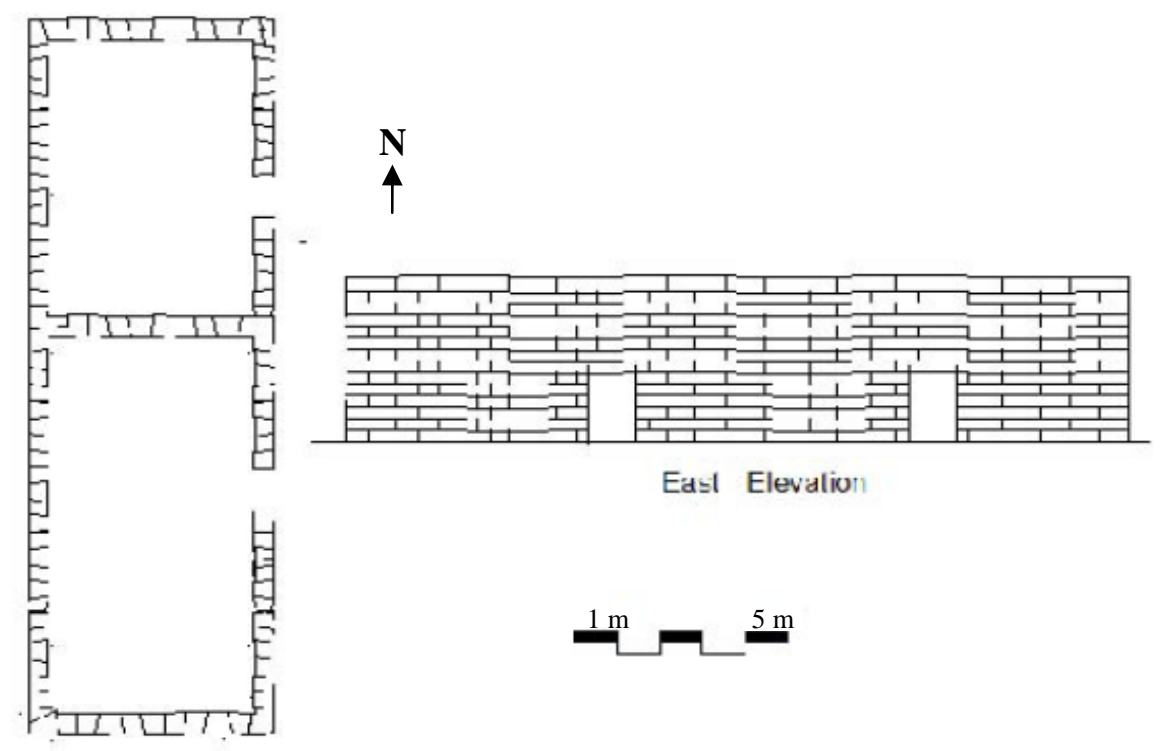

Fig. 4 Primitive pastoral housing-Housing of "Raffa Salameh Farraj Masaeed”.

of crude natural basalt stones and of mud blocks and modern manufactured cement material. All of these patterns including its tools were built in the same period, so that they can form a close architectural blocks. Each block consists of one room or several rooms in order to do different functions such as the residential function which specialized with the cement housing, and the mud housing that is built of mud blocks which are allocated to housing and storing as you can see in Fig. 5.

\section{The Constructional Development and the Beginning of the New Phase in Al Aqeb Town}

The late seventies and eighties had witnessed a major constructional development in $\mathrm{Al}$ aqeb town, the most important characteristics included the changing and development of residential settlement in houses that are made of stones and in dismissing tents as well, due to many important reasons. The most important one included the work of $\mathrm{Al}$ aqeb population, in other words, they start working at civilized jobs including governmental-military jobs that were able to reflect on the nature of the housing at the southern of al Badia of Jordan, and in Al aqeb town particularly since it is the current case of study and the research field. This stage is considered to be the beginning of modern stage in $\mathrm{Al}$ aqeb town and it has a lot of architectural patterns will mention some of it in a brief way. In the end of seventies of the last century, features of new architectural style began to appear in Al aqeb town in which the old style of building houses according to the traditional system has been discarded for ever so, that the use of basalt stones and mud are no longer fruitful. This transition confirmed in the architectural pattern the change the modern economic activities pattern and as a result, people of that town left their traditional living habit and moved to a modern one in so many different appearances in everyday life. The dwelling was carried out according to innovative engineering plans and now it consists of several rooms that are open internally to the distributor in which each room has a

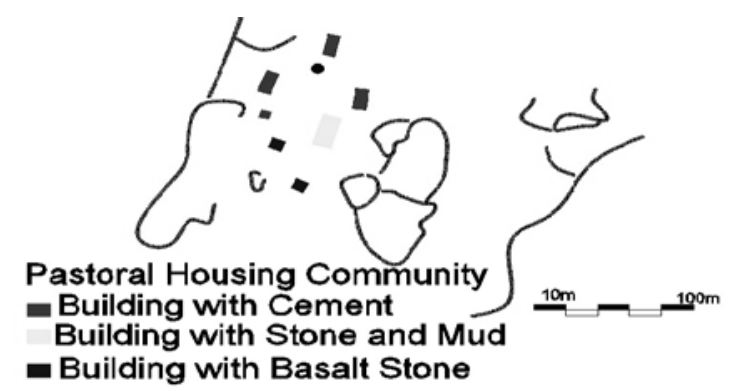

Fig. 5 Abandoned residential pastoral assembly, which is located southeast of the $\mathrm{Al}$ aqeb. 
specific function. Besides, a staircase had been fixed there in order to lead to the top roof and that is used by the family as an extra space for them. The dwelling is surrounded by fenced and planted courtyards with various types of fruitful forestry trees, and a vegetables farm that can benefit the family as in Fig. 6.

So in the early nineties of the last century, modern dwelling system had appeared that consist of white stone block as you can see in Fig. 7. Nowadays a new building block has been set up to the southern entrance of the town and to the international road where urbanization in $\mathrm{Al}$ aqeb town is in that direction.

\section{Conclusions and Recommendations}

Since $\mathrm{Al}$ aqeb was founded in the early thirties of the last century, it has traditionally depended on its

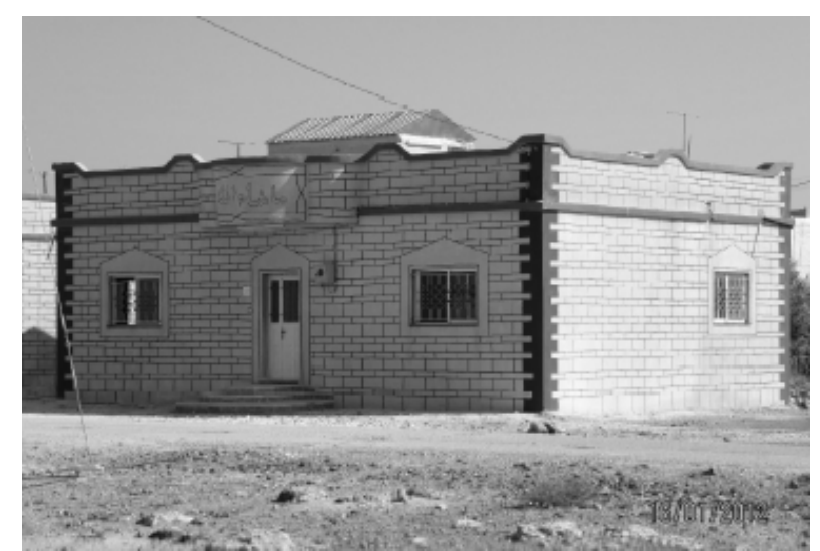

Fig. 6 The cemented building and the more developed model of the previous housing in terms of architectural construction.

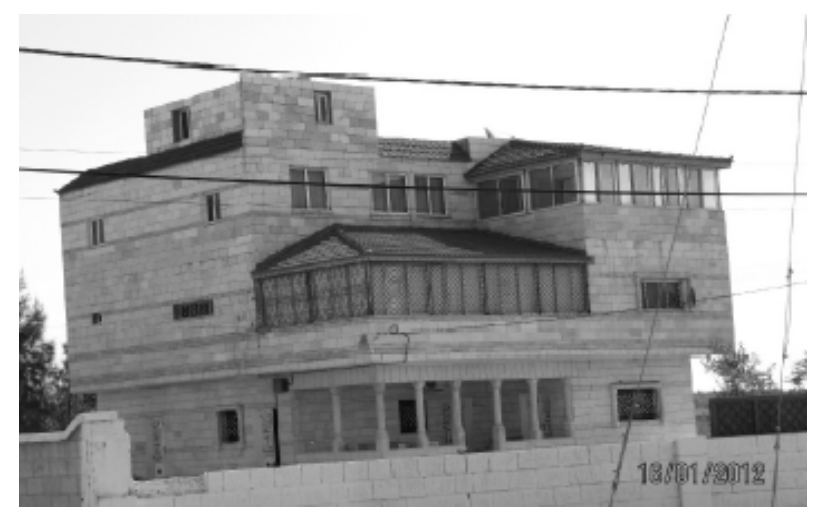

Fig. 7 This pattern is considered to be the newest one in Al aqeb town although it is far from the place privacy and its old heritage style. self-components and its vital atmosphere that consisted of the basin of $\mathrm{Al}$ aqeb valley, and it has tried as much as possible to benefit from the processes of development, modernity and the intervention of official development institutions to achieve a kind of life gain in the desert, where the developments have leaded to a radical changes, especially at the economic and physical side, and not mention that there was some kind of break with the traditional cultural heritage in which its manifestations are still visible in $\mathrm{Al}$ aqeb town. However, the heritage is objected to change and to lose its culture privacy, as well as it is exposed to the danger of disappearing for reasons related to social change and cultural circumstances in the traditional villages in al Badia of Jordan. As there are several factors affected the growth of the $\mathrm{Al}$ aqeb town that has the nature pastoral nomadic, it is socially and culturally noticed that social and cultural pattern form a response to the ecosystem and historical racialist and model of pastoral production, as well as it is observed the coexistence of traditional heritage at the physical and moral support with aspects of modernity that have occurred recently on the town and its inhabitants. But in terms of urbanization side they do not reflect the falling of the new buildings neither to their front parts, in which it contacts with the heritage or the expression of personal place and function of society.

The authors got some recommendations as following:

(1) Linking the society of the Northern Badia with an architectural style that can be compatible with the nature of their work;

(2) Linking the architectural style of the northern Badia with environment of the place and activating time;

(3) Re-reading the architectural style of the northern Badia in Jordan and find out the compatibility of this architecture with the history and thoughts of people and environment of the region, in order to measure the absence or presence of the human dimensions in the 
modern architecture in Badia;

(4) The importance of employing the concept of (historical, environmental, natural and social value) in sustainable construction development programs;

(5) Developing the conventional-hereditary methods of construction in Badia and adapting it to remain aligned with the spatial environment, social and cultural heritage for the people of Badia;

(6) To work on documentation of Badia heritage in various fields of social, cultural and constructivism.

\section{References}

[1] A.K.M. Ahmed, Desertification in Mafraq governorate-Study of the imbalance in the ecological balance, Master Thesis, University of Jordan, Jordan, 1987, pp. 19-22, 107.

[2] M. Abdul-Aziz, Survey Anthropological Fieldwork in the Northern Badia of Jordan, the First Phase, Al al-Bayt University Publication, Jordan-Mafraq, 1997, pp.
8-14.

[3] A.M. Nazir, Environments, Plants, Dry Areas and High Dry Area in Syria the Syrian-Protect and Develop, University of Aleppo, Syria, 1981, p. 14.

[4] S. Elyas, The Scientific for the Mafraq Governorate, $\mathrm{Al}$ al-Bayt University Publication, Jordan-Mafraq, 1997, pp. 14-16.

[5] A.H.A. Mahmoud, Mafraq Governorate and Its Surroundings-A Trip through the Ages, Archaeological Studies and Surveys, Al-Arz Presses, Amman, Jordan, 1999, p. 636.

[6] H.C. Butler, E. Littmann, E. Stoever, Publications of the Princeto University Archaeological Expedition to Syrian, 1904-5 and 1909, E.J. Brill, Leyden, 1930.

[7] B. de Vries, U. el-Jimal, A Frontier Town and Its Landscape in Northern Jordan, Fieldwork 1972-1981, Journal of Roman Archaeology Supplementary Series 1 (1998) 115-116.

[8] D. Veries, Urbanization in the Basalt Region of North Jordan in Lat Antiquity: The Case Study of Umm El-Jimal, Studies in the History and Archaeological of Jordan, Umm El-Jimal, 1985. 